\title{
Can changes in ice-sheet flow be inferred from crystallographic preferred orientations?
}

\author{
Maria-Gema Llorens $^{1 *}$, Albert Griera ${ }^{2}$, Paul D. Bons ${ }^{3,4}$, Ilka Weikusat ${ }^{3,5}$, David Prior ${ }^{6}$, \\ 5 Enrique Gomez-Rivas ${ }^{7}$, Tamara de Riese ${ }^{3}$, Ivone Jimenez-Munt ${ }^{1}$, Daniel García-Castellanos ${ }^{1}$ \\ and Ricardo A. Lebensohn ${ }^{8}$ \\ ${ }^{1}$ Geosciencies Barcelona CSIC, Lluis Sole i Sabaris s/n, 08028 Barcelona, Spain \\ 2 Departament de Geologia, Universitat Autònoma de Barcelona, 08193 Cerdanyola del Vallès, Barcelona, \\ 10 Spain \\ ${ }^{3}$ Department of Geosciences, Eberhard Karls University Tübingen, Wilhemstr. 56, 72074 Tübingen, Germany \\ ${ }^{4}$ China University of Geosciences, Beijing, China \\ ${ }^{5}$ Alfred Wegener Institute Helmholtz Centre for Polar and Marine Research, Germany \\ ${ }^{6}$ Department of Geology, University of Otago, 362 Leith Street, Dunedin 9016. New Zealand \\ $15{ }^{7}$ Departament de Mineralogia, Petrologia i Geologia Aplicada, Facultat de Ciències de la Terra, Universitat de \\ Barcelona, Martí i Franquès s/n, 08028 Barcelona, Spain \\ ${ }^{8}$ Theoretical Division. Los Alamos National Laboratory. Los Alamos, NM, 87545, USA \\ *Corresponding author: mgllorens@geo3bcn.csic.es (Maria-Gema Llorens) \\ 20
}

Keywords: ice microstructures, crystallographic preferred orientation, ice-sheet flow, finite strain, flow transitions

\section{Abstract}

25

Creep due to ice flow is generally thought to be the main cause for the formation of crystallographic preferred orientations (CPOs) in polycrystalline anisotropic ice. However, linking the development of CPOs to the ice flow history requires a proper understanding of the ice aggregate's microstructural response to flow transitions. In this contribution the influence of ice deformation history on the CPO development is investigated by means of full-field numerical simulations at the microscale. We simulate the CPO evolution of polycrystalline ice under combinations of two consecutive deformation events up to high strain, using the code VPFFT/ELLE. A volume of ice is first deformed under co-axial 
boundary conditions, which results in a CPO. The sample is then subjected to different boundary conditions (co-axial or non-coaxial) in order to observe how the deformation regime switch impacts on the $\mathrm{CPO}$. The model results indicate that the second flow event tends to destroy the first, inherited fabric, with a range of transitional fabrics. However, the transition is slow when crystallographic axes are critically oriented with respect to the second imposed regime. Therefore, interpretations of past deformation events from observed CPOs must be carried out with caution, particularly, in areas with complex deformation histories.

\section{Introduction}

During the last two decades sea level rise has accelerated in association with global climate change (Nerem et al., 2018), but the limited knowledge available on how fast ice flows in ice sheets along with uncertain boundary conditions (Edwards et al., 2021), give a wide range in long-term sea level rise predictions. The rheological changes of polar ice during its deformation are crucial for the accurate projection of ice sheet discharge into the ocean (Golledge et al., 2015). Ice at Earth surface conditions (ice $1 h$ ) flows driven by stress caused by gravity in glaciers, ice sheets and ice shelfs (e.g., Hudleston, 2015). Crystal-plastic strain of ice is mainly accommodated by the glide of dislocations along their individual crystallographic slip systems (Duval, 1983). Deformation of a grain aggregate by dislocation creep leads to a crystallographic preferred orientation (CPO), also called fabric. The CPO evolves according to the flow kinematics, magnitude of strain and temperature (Budd and

55 Jacka, 1989; Katayama and Karato, 2006), and importantly on the activity of, or ease of glide of dislocations on the different slips systems. An ice crystal is strongly anisotropic, because it deforms predominantly by the glide of dislocations on the basal plane (0001) and along the $a$ axes $<11-20>$ direction (Duval et al., 1983). The gravity-driven flow of ice sheets produces rotations of ice crystal lattices, developing CPOs according to the stress configuration

60 (Treverrow et al., 2012). The $c$-axes (normal to the basal plane) tend to get oriented parallel to the maximum compressional finite strain, while the $a$-axes tend to be parallel to the maximum extensional finite strain. For that reason, the observed CPO in ice cores drilled in ice sheets and glaciers is assumed as a reliable macroscopic flow indicator (Alley and Joughin, 2012). Microstructures described from ice cores drilled in Antarctica and Greenland have allowed the interpretation of deformation conditions (see table 1 in Faria et al., 2014). However, because ice can be affected by differences in temperature and stress configurations during ice-sheet flow, unravelling the ice deformation history from $c$-axis fabrics observed in 
natural ice samples can be challenging. The fact that most deep ice cores are mostly drilled at ice-sheet divides or domes, with the aim of providing the best-quality paleoclimate record, does not help in gaining understanding of natural ice flow from the recovered ice samples. Most of the current knowledge of the link between ice deformation and $\mathrm{CPO}$ development is derived from laboratory experiments. Experimental studies have utilised ice to understand how CPOs develop and evolve under deformation (e.g., see Durham et al., 1983 and many others). Most studies by far use bulk isotropic ice (i.e., with a random CPO) that is then subjected to a single deformation event. Due to the limitations of laboratory deformation experiments, to our knowledge only a few studies have used polar ice samples starting with a pre-existing CPO. Moreover, most of such studies focused on vertical uniaxial compression of samples with a pre-existing CPO that was formed by vertical compression (resulting in a caxis cluster or cone) (Azuma and Higashi, 1984; Gao and Jacka, 1987; Dahl-Jensen et al., 1997, Castelnau et al., 1998). Exceptions are the experiments by Jun and Jacka (1998) and Treverrow et al. (2012), in which the compressional CPO is deformed under horizontal shear, and Craw et al. (2018), where vertical axial compression is applied to sub-samples taken at different angles from a sample with a pre-existing vertical girdle orientation. Numerical modelling provides an alternative approach to overcome these limitations because it allows a continuous analysis of multiple deformation scenarios with a wide variety of deformation kinematics and environmental parameters. Moreover, numerical simulations of polycrystalline ice and their comparison with experimental and natural data provide useful insights into the study of the CPO development, as they allow visualizing and quantifying the microstructural evolution up to high strain (Montagnat et al., 2014b; Llorens et al., 2016a 2016b; 2019; 2020; Piazolo et al., 2019). However, as in the case of laboratory experiments, most numerical studies to date have focused on systems starting with an initially random $\mathrm{CPO}$ to which a single deformation event is applied. Although very useful, these experimental and numerical studies can only represent a limited range of real natural scenarios, where ice aggregates with no strain history are subjected to stress. To date there are no systematic studies providing a comprehensive understanding of the evolution of polycrystalline ice that has previously experienced flow. An exception is the work of Jansen et al. (2016), where the viscoplastic response of ice polycrystals with a starting CPO is analysed to explain the formation of small-scale folds in cloudy bands. Considering that polar ice typically experiences multiple changes in deformation regime 100 during ice-sheet flow, systematic studies of CPO development during multi-stage deformation histories are essential. Hence, this contribution intends to fill this knowledge gap 
by providing a study of the multi-stage deformation of ice samples and the resulting CPOs for different settings. We present a series of numerical simulations of polycrystalline ice that is affected by two consecutive deformation events. We choose combinations of subsequent deformation kinematics that may be expected to occur in ice sheets. We analyse the CPO developed during these deformation events in order to determine the kinematic conditions for the preservation, modification or destruction of CPO's in ice.

\section{Flow regime transitions in polar ice sheets}

We analyse different examples of flow changes that represent relevant and/or common deformation regimes in ice sheets. Ice flows in all directions from the accumulation zone towards the edges of the ice mass driven by the gravity force. Due to precipitation and accumulation, ice is gradually compressed ranging from vertical axial compression in domes, to plane strain vertical compression in ridges (zone I in Fig. 1a). Evidence for extensional flow transverse to the ridge has been found in ridges (Fig. 1b), as in the NorthGRIP (Wang et al., 2002; Faria et al., 2014) and EDML ridges (Weikusat et al., 2017).

(a)

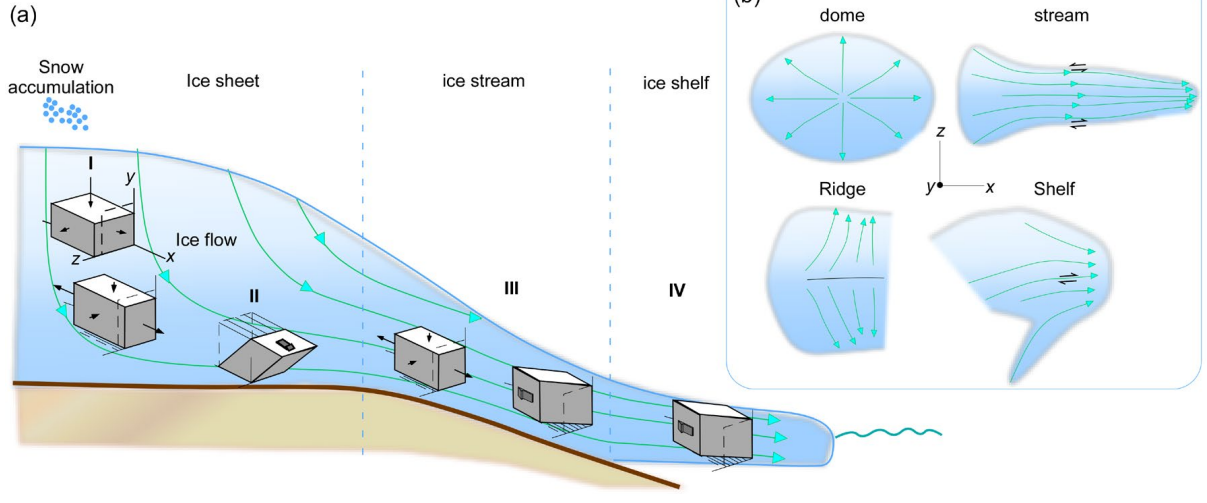

Figure 1. Sketch of ice-sheet flow patterns in (a) cross section and (b) map view, showing some dominant deformation conditions at different zones of the ice mass. At the upper and central parts of the dome the dominant flow regime is vertical axial compression parallel to $y$ (indicated by zone I). In ice ridges, an extension flow transverse to the ridge can occur (Wang et al., 2002). Flow turns progressively more non-coaxial with depth and distance from the dome, where strongly non-coaxial deformation dominates close to the bedrock (indicated by zone II). The dominant kinematic regime at the ice stream is extension along the flow direction, where simple shear deformation with a vertical shear plane can occur in shear margins of the stream (indicated by zone III). At the ice shelf, the predominant regime assumed in this contribution is simple shear with vertical shear plane (zone IV) (Lutz et al., 2020). 

acceleration may dominate, resulting in extension along the flow direction (zone III in Fig. 1a). In a shear margin of glaciers and ice streams, as well as in some ice shelves, ice experiences a gradient in velocity in the lateral direction perpendicular to that velocity, resulting in simple shear deformation with a vertical shear plane (zone III and IVa in Fig.1ab) (Young et al., 2002; LeDoux et al., 2017; Lutz et al., 2020). Notice that, in the presented configuration the $x y z$ reference frame is defined with $y$ vertical, $x$ horizontal and parallel to flow and $z$ normal to $x y$.

\section{Methods}

\subsection{Numerical simulation of ice fabrics and postprocessing}

Ice polycrystalline viscoplastic deformation was simulated using the Fast Fourier Transform algorithm (VPFFT; Lebensohn and Rollett, 2020), within the numerical open-source platform ELLE (http://www.elle.ws; Bons et al., 2008). ELLE has been successfully used for the simulation of a variety of studies of rock microstructure evolution during deformation and metamorphism (see Piazolo et al., 2019). The coupling of the full-field VPFTT code and ELLE allows simulating deformation of a polycrystalline aggregate by dislocation glide up to high strains $(>10)$ as often found in nature in ice and rocks. The reader is referred to Lebensohn and Rollett (2020) for a detailed description of the VPFFT approach, and to Griera et al. (2013) and Llorens et al. (2016a) for a detailed description of the coupling between VPFFT and ELLE. The local mechanical response of a nonlinear heterogeneous material can be calculated as a convolution integral of the Green functions associated with a linear homogenous medium and a polarisation field. The VPFFT formulation is used to transform the polarisation field that contains all the information on the heterogeneity and non-linearity of the material's behaviour into Fourier space. By the conversion of the real space convolution integrals to simple products in the Fourier space, the mechanical fields are calculated, and the convolution product is transformed back to real space. In this full-field approach, the semi two-dimensional data structure is discretised by a regular mesh of 256x256 unconnected nodes (unodes) or Fourier points (Fig.2). The strain rate and stress field under compatibility and equilibrium constraints related by the constitutive equation (1) 
is obtained by an iteratively solving for the flow law for every unode $(u)$ :

Where $\dot{\varepsilon}_{i j}$ is the strain rate, $\sigma_{i j}^{\prime}$ is the deviatoric stress, $m_{i j}^{S}$ is the symmetric Schmid tensor, $\dot{\gamma}^{s}$ the shear strain rate, $\tau^{s}$ is the critical resolved shear stress defined for the slip system $\left(N_{s}\right)$, $\dot{\gamma_{0}}$ is a reference strain rate and $n$ is the rate sensitivity exponent. In all three slip systems, the shear strain rate is assumed to be related to the deviatoric stress by a stress exponent of $n=3$, in accordance with the "Glen's law" (Haefeli,1961). After convergence, the VPFFT code calculates the associated lattice rotations from the velocity gradient and stress fields. The actual stress exponent in ice $1 \mathrm{~h}$ may actually be closer to $n=4$ (Bons et al., 2018). The first tests show that raising $n$ to 4 has little effect on the CPO, and in order to be coherent with previous ice CPO simulations (Llorens et al., 2016a, 2016b, Steinbach et al., 2016, Jansen et al., 2016; Qi et al., 2018; Piazolo et al., 2019) all simulations presented here are carried out with the more commonly used $n=3$. Uniaxial shortening of a single crystal by glide along the non-basal planes only requires about 60 times higher stress than when the crystal can deform entirely by basal-plane glide (Duval et al., 1983). We therefore set $\tau^{s} 60$ times lower for basal glide than for prismatic and pyramidal glide. Previous numerical studies have shown that about the same single-maximum CPO develops at low temperature and a high strain rate conditions, regardless of the set rate of dynamic recrystallisation (Llorens et al., 2016a; 2016b). As this contribution aims to study the CPO response to a change in the deformation regime, the numerical procedures that simulate dynamic recrystallisation are deliberately not incorporated in this study. Every unode represents a crystallite where the crystal orientation, strain rate, dislocation density and local stress is stored (Fig.2b). All unodes within a grain have the same initial crystal orientation (Fig.2a). The crystal orientation is defined by the three Euler angles. We use the three Euler angles stored at every unode of the model for the calculation of the orientation density function (ODF), which provides the orientation densities in Euler space, using the opensource texture analysis software MTEX (Bachmann et al., 2011). The intensity of the CPO is shown by the misorientation index (M-index; Skemer et al., 2005) calculated from the ODF. Crystal symmetry indices are shown as the proportion of point, girdle and random components of the $\{0001\}$ crystallographic axis, or c-axis distribution, calculated from the 

to Llorens et al. (2016a).

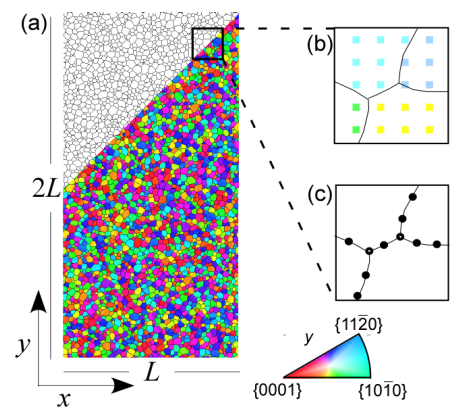

Figure 2. (a) The initial microstructure has $2 \times 1$ model unit length $(L)$. The inverse pole figure (IPF) color-code indicates the lattice orientation with respect to the $y$-direction. Two data layers are used in ELLE: (b) the microstructure is discretised in a mesh of 256x256 Fourier points (also termed unconnected nodes or unodes), and (c) a boundary node (bnodes) layer that define grains as polygons.

\subsection{Simulated flow regimes and applied boundary conditions}

Deformation was applied to the microstructure by incremental steps of a shear strain of $\gamma=0.04$ or, alternatively, $2 \%$ of shortening or extension (Table 1), both equivalent to 0.02 of natural strain, defined as $\ln \left(L_{f} / L_{i}\right)$ (with $L_{f}$ and $L_{i}$ being the final and initial length of a line in the direction of maximum extension, respectively). Each examples considered in this contribution consists of two deformation regimes that are applied in succession (see Table 2). We considered four different model series to simulate flow transitions according to combinations of deformation regimes described in Figure 1.

Table 1. Velocity gradient tensors $\mathbf{V}$ considered for the different regimes $\left(\times 10^{-8} \mathrm{~s}^{-1}\right)$ and corresponding zones in

Figure 1. The $x y z$ reference frame is defined with $y$ vertical, $x$ horizontal and parallel to flow and $z$ normal to $x y$ :

\begin{tabular}{|c|c|c|c|}
\hline Name & Regime & $\begin{array}{c}\text { Zone } \\
\text { (Figure 1) }\end{array}$ & \multicolumn{3}{|c|}{$\begin{array}{c}\text { Velocity gradient } \\
\text { tensor }\end{array}$} \\
\hline $\mathbf{V}_{\mathbf{1}}$ & Vertical uniaxial & I & {$\left[\begin{array}{ccc}0.01 & 0 & 0 \\
0 & -0.02 & 0 \\
0 & 0 & 0.01\end{array}\right]$} \\
& compression parallel to $y$, & & \\
\hline $\mathbf{V}_{\mathbf{2}}$ & Horizontal dextral simple & II & {$\left[\begin{array}{ccc}0 & 0.04 & 0 \\
0 & 0 & 0 \\
0 & 0 & 0\end{array}\right]$} \\
\hline
\end{tabular}




\begin{tabular}{|c|c|c|c|}
\hline \multirow{2}{*}{} & strain & & \\
\hline $\mathbf{V}_{\mathbf{3}}$ & Horizontal uniaxial & I, III & {$\left[\begin{array}{ccc}0.02 & 0 & 0 \\
0 & -0.01 & 0 \\
0 & 0 & -0.01\end{array}\right]$} \\
& extension parallel to $x$, & & \\
\hline $\mathbf{V}_{\mathbf{4}}$ & compression in $y$ and $z$ & & {$\left[\begin{array}{ccc}0 & 0 & -0.04 \\
0 & 0 & 0 \\
0 & 0 & 0\end{array}\right]$} \\
& Vertical dextral simple & III, IV & \\
& shear on plane $x z$, plane & & \\
\hline
\end{tabular}

\subsubsection{Series A: Ice flowing from the centre of the dome to deep lateral zones}

Snow precipitation at a dome causes vertical uniaxial compression and flattening of ice layers, and outflow in all horizontal directions (zone I in Fig. 1). As ice flows away from domes and gets buried deeply it enters the zone dominated by simple shear parallel to the bedrock (zone II in Fig. 1). To simulate this transition, we carried out a series of simulation with first vertical uniaxial compression parallel to $y\left(\mathbf{V}_{\mathbf{1}}\right)$, followed by dextral simple shear on horizontal plane $x z\left(\mathbf{V}_{2}\right)$ (Table 1 and 2).

Table 2. Deformation regimes applied to the different series of numerical simulations, including idealised deformation regimes in drill cores and examples.

\begin{tabular}{|l|l|l|l|l|}
\hline Name & $\begin{array}{l}\text { First + Second } \\
\text { regime }\end{array}$ & $\begin{array}{l}\text { Application of the } \\
\text { second regime }\end{array}$ & \multicolumn{1}{|c|}{ Ice core } & \multicolumn{1}{|c|}{$\begin{array}{c}\text { Drill core } \\
\text { regime }\end{array}$} \\
\hline Series A & $\mathbf{V}_{\mathbf{1}}+\mathbf{V}_{\mathbf{2}}$ & $\begin{array}{l}\text { At the last step } \\
\left(\varepsilon_{l}=0.92\right)\end{array}$ & $\begin{array}{l}\text { GRIP, } \\
\text { GISP2, Dome } \\
\text { C, Dome F, } \\
\text { Talos Dome }\end{array}$ & Dome/Summit \\
\hline Series B & $\mathbf{V}_{\mathbf{3}}+\mathbf{V}_{\mathbf{2}}$ & $\begin{array}{l}\text { At the last step } \\
\left(\varepsilon_{l}=0.92\right)\end{array}$ & $\begin{array}{l}\text { NorthGrip, } \\
\text { EDML, } \\
\text { NEEM }\end{array}$ & Divide \\
\hline Series C & $\mathbf{V}_{\mathbf{1}}+\mathbf{V}_{\mathbf{3}}$ & $\begin{array}{l}\text { At steps of } \varepsilon_{l}=0,0.2, \\
0.4,0.8 \text { and } 1.2\end{array}$ & Spice, Vostok & Flank flow \\
\hline Series D & $\mathbf{V}_{\mathbf{3}}+\mathbf{V}_{\mathbf{4}}$ & $\begin{array}{l}\text { At the last step } \\
\left(\varepsilon_{l}=0.92\right)\end{array}$ & Shear margin \\
\hline
\end{tabular}




\subsubsection{Series B: Ice flowing from the centre of the ridge to deep lateral zones}

On ridges away from ice domes, ice flows away and stretches in the direction perpendicular to the ridge (Wang et al., 2002; Faria et al., 2014) (zone I in Fig. 1). Here we consider the end-member case that this leads to uniaxial extension in the flow direction. Similar to Series A, the ice is then assumed to be buried and to enter zone II (Fig. 1) where flow is dominated by bedrock-parallel simple shear, again in the direction perpendicular to the ridge (zone II in Fig. 1). For this case, we considered simulations in which a polycrystalline ice aggregate is first deformed by $\mathbf{V}_{\mathbf{3}}$, horizontal uniaxial extension parallel to $x$, followed by $\mathbf{V}_{\mathbf{2}}$, dextral simple shear on horizontal plane $x z$ (Table 1 and 2).

\subsubsection{Series C: Ice flowing from an ice dome to an ice flank or stream}

In this configuration we assume that ice is first gradually flattened by vertical uniaxial compression parallel to $y$ in the ice dome ( $\mathbf{V}_{\mathbf{1}}$; zone I in Fig. 1) and subsequently enters a zone in which the flow accelerates in, for example, an ice stream, leading to uniaxial extension in the flow direction $\left(\mathbf{V}_{\mathbf{3}}\right.$; zone III in Fig. 1). Series $\mathrm{C}$ simulations include a set of simulations where $\mathbf{V}_{\mathbf{3}}$ deformation starts at different strains in the first stage with $\mathbf{V}_{\mathbf{1}}$.

\subsubsection{Series D: Ice flowing from an ice-stream or glacier to an ice shelf or shear margin}

Dominantly simple shear deformation with a vertical shear plane takes place in the margins of ice streams (Hudleston, 2015) and can be found in some ice shelves (Young et al., 2002; LeDoux et al., 2017; Lutz et al., 2020) (zone IV in Fig.1). Ice affected by this shearing may have experienced different deformation types. Here we consider the case of uniaxial extension in the flow direction (zone III in Fig.1), which would represent the ice above the deepest layers, that thus did not experience of bedrock-parallel simple shear before. A series of simulations were run to simulate the scenarios involved in this scheme: first uniaxial extension in the $x$ direction $\left(\mathbf{V}_{\mathbf{3}}\right.$; zone III in Fig. 1), and subsequently dextral simple shear on vertical plane $x y\left(\mathbf{V}_{\mathbf{4}}\right.$; zone IV in Fig. 1).

\section{CPO evolution results}

\subsection{Series A: Ice flowing from the centre of the dome to deep lateral zones}


The pole figures in Figure 3 show the crystallographic preferred orientation evolution during deformation in Series A. The initially untextured microstructure (i.e., with an initially homogeneous and random lattice orientation, see Fig. 3a) develops a strong CPO due to the rotation of c-axes towards the maximum shortening direction, according to the imposed vertical compression (see Fig.3a at $\varepsilon_{I}=0.92$ ). The observed CPO symmetry, expressed as the proportion of point $(\mathrm{P})$, girdle $(\mathrm{G})$ and random $(\mathrm{R})$ components of c-axes $\{0001\}$, is characterised by a point maximum with a minor girdle component (Fig. 3c). The final step of the first regime $\left(\varepsilon_{l}=0.92\right)$ is used as the initial texture for the second deformation regime simulation, where the aggregate is subjected to horizontal top-to-the-right simple shear up to a total natural strain of 4 (see $\varepsilon_{2}=3$ Fig. 3 b).

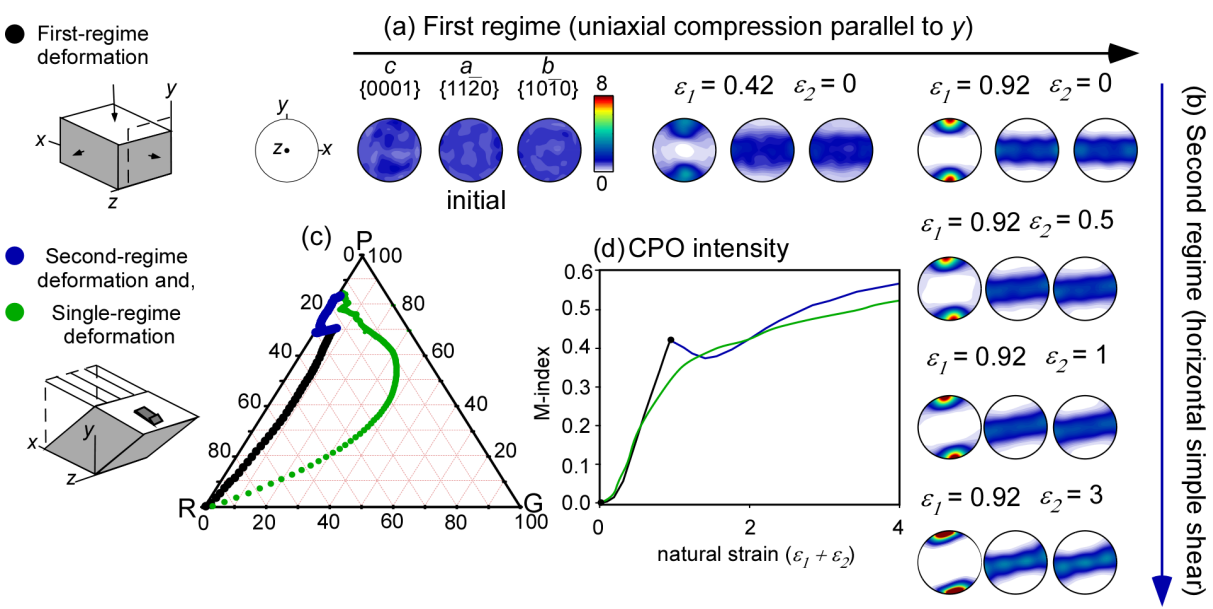

Figure 3. $\mathrm{CPO}$ evolution during the two consecutive deformation regimes of series A: (a) vertical uniaxial compression parallel to $y$ (red) and subsequently (b) dextral simple shear on horizontal plane $x z$ (blue). The final texture developed at the end of the first flow regime is used as the initial texture (input) for simulating the second regime. (c) Ternary diagram that shows the CPO symmetry expressed as the proportion of point (P), girdle $(\mathrm{G})$ and random $(\mathrm{R})$ components of c-axes $\{0001\}$. Points plotted at the PGR graph represent every step of deformation $(\varepsilon=0.02$ ). (d) The CPO intensity is quantified as the M-index from the ODF (misorientation index, Skemer et al., 2005) and its evolution with cumulative strain so shown. The evolution of the CPO in simple shear only, starting with a random fabric (single-regime deformation), is shown in green in both (c) and (d).

At the beginning of the second regime the CPO slightly rotates antithetically (i.e., opposite to the imposed shear sense) (see $\varepsilon_{2}=1$ in Fig. 3b), while the CPO intensity (Fig. 3d) and girdle component decrease (Fig. 3c). After that the CPO intensity (point maximum) gradually 
intensifies again and the c-axes align at about $10^{\circ}$ to the normal to the shear plane (see $\varepsilon_{2}=3$ in

Fig. 3b and Fig. 3c). After the two deformation events the resulting CPO resembles the one resulting from simple shear deformation only, in both CPO intensity and symmetry (green and blue markers in Fig. 3d and Fig. 3c). This implies that the previous uniaxial flattening regime is not recognizable after only a moderate amount $\left(\varepsilon_{1}>1\right)$ of subsequent simple shear, as may be expected as the change in CPO only involves a small rotation and intensification of the c-axes point maximum.

\subsection{Series B: Ice flowing from the centre of the ridge to deep lateral zones}

In series B, the initially random distributed c-axes develop a CPO characterised by a strong vertical girdle, in coherence with the horizontal extension applied at the first deformation regime (see $\varepsilon_{1}=0.92$ in Fig. $4 a$ ). From the final step onwards, the aggregate is deformed under horizontal top-to-the-right simple shear up to a natural strain of $\varepsilon_{2}=4$ (Fig. 4 b). C-axes reorient following the new flow, destroying the vertical girdle fabric (Fig. 4c), and forming a broad single point maximum almost normal to the shear plane (see $\varepsilon_{2}=4$ in Fig. $4 b$ ). Although the final CPO symmetry is coherent with simple shear deformation, its shape after a strain of $\varepsilon_{2}=4$ still differs from that of the previous case (series A) or that of simple shear only (see the last step for the second regime in Figs. $3 \mathrm{a}$ and $4 \mathrm{a})$. At the highest modelled strain $\left(\varepsilon_{2}=4\right)$ the CPO intensity is clearly lower than that developed under solely simple shear deformation

(Fig. 4d). Changing a girdle to point maximum requires a significantly higher strain than the formation of a point maximum only (green versus blue graph in Fig.4d).

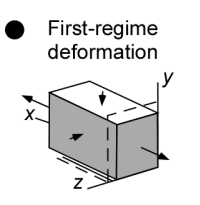

Second-regime Second-regime
deformation and,

- Single-regime
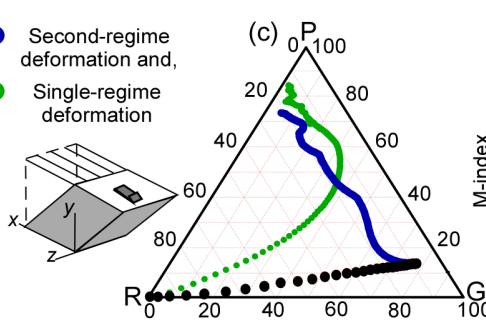

(c) ${ }_{0} P_{100}$ (a) First regime (horizontal uniaxial extension parallel to $x$ )
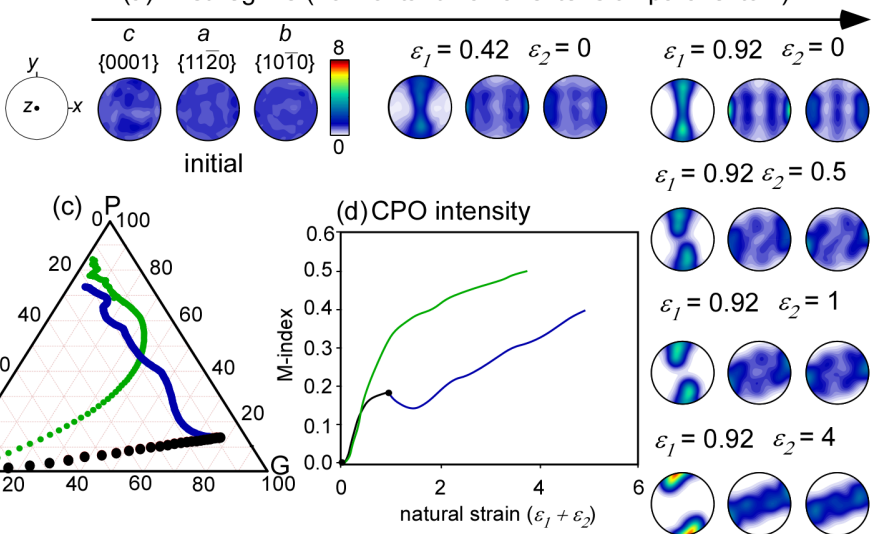

$\varepsilon_{1}=0.92 \varepsilon_{2}=0.5$

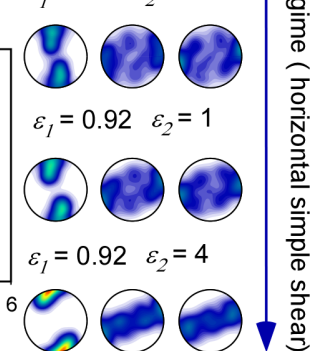

Figure 4. CPO evolution during the two consecutive deformation regimes of series $\mathrm{B}$. The final texture at the 
end of the first flow regime (a), is used as initial texture for the second regime (b). (c) Ternary diagram that shows the CPO symmetry expressed as the proportion of point $(\mathrm{P})$, girdle $(\mathrm{G})$ and random $(\mathrm{R})$ components of caxes $\{0001\}$. Points plotted at the PGR graph represent every step of deformation $(\varepsilon=0.02)$. (d) The CPO intensity is quantified as the M-index from the ODF. The evolution of the CPO in simple shear only, starting with a random fabric (single-regime deformation), is shown in green in both (c) and (d).

\subsection{Series C: Ice flowing from an ice dome to an ice flank or stream}

The microstructure in series $\mathrm{C}$ first develops a strong CPO (Fig. 5b) with a point maximum in the $y$-direction of the axial compression applied during the first deformation regime (see first row in Fig. 5a). In this series the second deformation regime was applied at different steps of natural strain of the first regime (at $\varepsilon_{1}=0.2,0.4,0.8$ and 1.2 , respectively). The intensity of the initial deformation regime has a notable influence on the CPO developed during the second regime. In the absence of first-regime deformation $\left(\varepsilon_{1}=0.0\right)$, where the microstructure only experiences uniaxial extension in the $x$-direction, a vertical girdle fabric develops (see first column in Fig. 5a and green marker Fig. 5b). Regardless of the step at which the second regime is applied, the CPO tends to evolve towards a girdle fabric (see evolution of all series in Fig. 5a-b), which reduces slightly the CPO intensity (Fig. 5c). If the second deformation regime is applied when the microstructure has only been slightly affected by the first regime $\left(\varepsilon_{1}<0.4\right)$, the c-axes tend to rotate forming a final girdle fabric but with a recognizable point maximum component, resulting in an "hourglass shape" (see second and third columns in Fig. 5a). However, if a strong point maximum $\mathrm{CPO}$ has been developed during the first deformation regime $\left(\varepsilon_{1}>0.8\right)$, the second regime cannot modify the inherited c-axis orientation at a natural strain of $\varepsilon_{2}=1.2$ (see fifth column in Fig. 5a), and the final CPO continues being dominated by a strong point maximum (Fig. 5b). The effect of the second regime is observable in the $a$-axis distribution, because regardless of the intensity of the first regime, the extension along the x direction produces three $a$-axis maxima (see last row in Fig. 5a). The result suggests that converting a point maximum into a girdle takes even more strain than the opposite (Series B). 


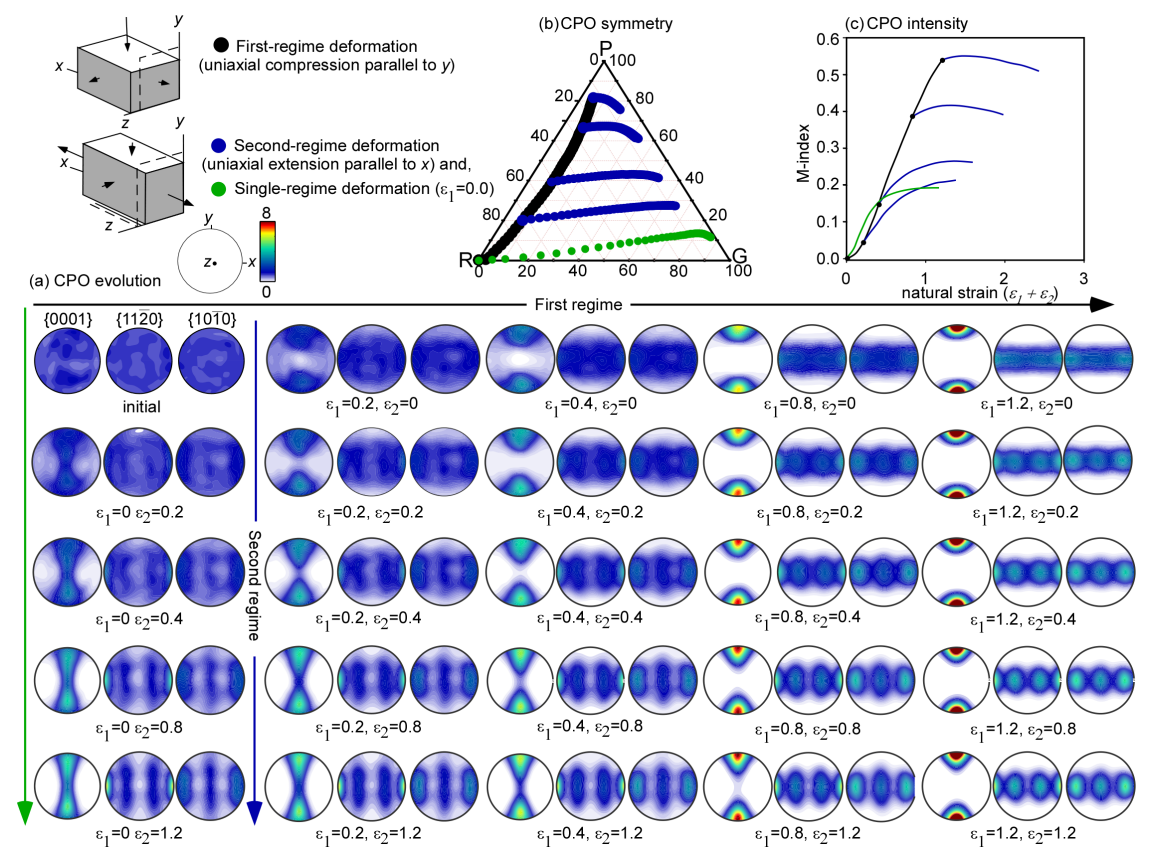

Figure 5. (a) $\mathrm{CPO}$ evolution during two consecutive deformation regimes of series $\mathrm{C}$. Textures developed at different steps of natural strain in the first regime $\left(\varepsilon_{l}\right)$ are used as initial textures for the second regime $\left(\varepsilon_{2}\right)$. (b)

Ternary diagram that shows the CPO symmetry expressed as the proportion of point $(\mathrm{P})$, girdle $(\mathrm{G})$ and random (R) components of c-axes $\{0001\}$. (c) The CPO intensity is quantified as the M-index from the ODF. The evolution of the CPO in uniaxial extension parallel to $x$ only, starting with a random fabric $\left(\varepsilon_{l}=0\right.$ : single-regime deformation), is shown in green in both (b) and (c).

\subsection{Series D: Ice flowing from an ice-stream or glacier to an ice shelf or shear margin}

In series $\mathrm{D}$ a vertical girdle fabric develops during the first deformation regime $\left(\varepsilon_{l}=0.92\right.$ in Fig. 6a), which then rapidly evolves towards a point maximum due to simple shear along a vertical shear plane imposed during the second flow regime (Fig. 6b). However, after significant strain there is still a girdle component. 


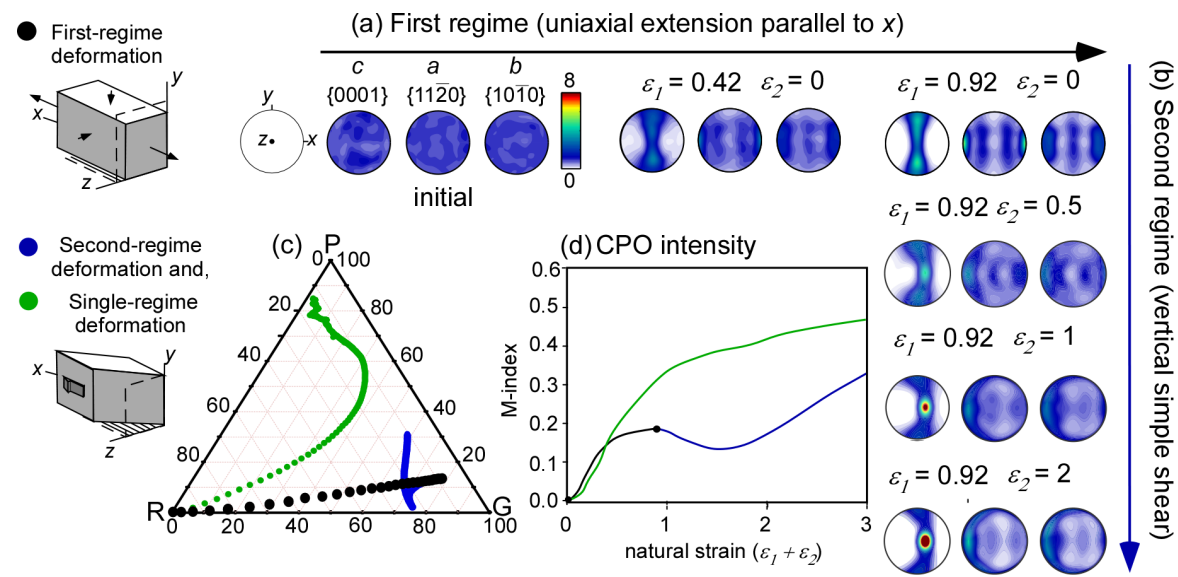

Figure 6. $\mathrm{CPO}$ evolution during the two consecutive deformation regimes of series $\mathrm{D}$. The final texture at the end of the first regime (a), is used as initial texture for the second regime (b). (c) Ternary diagram that shows the CPO symmetry expressed as the proportion of point $(\mathrm{P})$, girdle $(\mathrm{G})$ and random $(\mathrm{R})$ components of c-axes $\{0001\}$. Points plotted at the PGR graph represent every step of deformation $(\varepsilon=0.02)$. (d) The CPO intensity is quantified as the M-index from the ODF. The evolution of the CPO in simple shear only (single-regime deformation), starting with a random fabric, is shown in green in both (c) and (d).

\section{Discussion}

Experiments and simulations with an initial random distribution of crystallographic orientations predict a quick alignment of the crystallographic axes according to the imposed deformation conditions (Azuma and Higashi, 1984; Qi et al., 2017, Llorens et al., 2016a; Llorens et al., 2016b). The types and orientations of CPO's are best described in terms of the principal axes of the finite-strain ellipsoid (FSE), also known as finite stretching axes (FSA's) that are typically labelled $X, Y$ and $Z$ from longest to shortest (Fig.7) (Passchier, 1990). These axes are parallel to the instantaneous stretching axes (ISA's) in the case of coaxial deformation, but not in the case of simple shear. C-axes tend to align themselves parallel to the shortening FSA's. In the case of uniaxial compression ( $\mathbf{V}_{\mathbf{1}}$ in Table $\left.1 ; X=Y>Z\right)$ this leads to the development of a strong point maximum. A girdle forms in uniaxial extension $\left(\mathbf{V}_{\mathbf{3}}\right.$ in Table $1 ; X>Y=Z)$. In simple shear $\left(\mathbf{V}_{\mathbf{2}}\right.$ and $\left.\mathbf{V}_{\mathbf{4}}\right)$ the orientation of the Z-axis rotates from initially $45^{\circ}$ to $0^{\circ}$ to the shear plane at infinite strain, while the $\mathrm{X}$-axis remains in the shear plane. A point-maximum CPO is expected and observed parallel to $Z$ in the plane between the instantaneous shortening axis and the normal to the shear plane. $a$-axes $\{11-20\}$ align themselves perpendicular to the c-axes in the plane of the two least compressive FSA's (i.e. the $X$ and $Y$-axes of the FSE) (see first column in Fig. 7). 


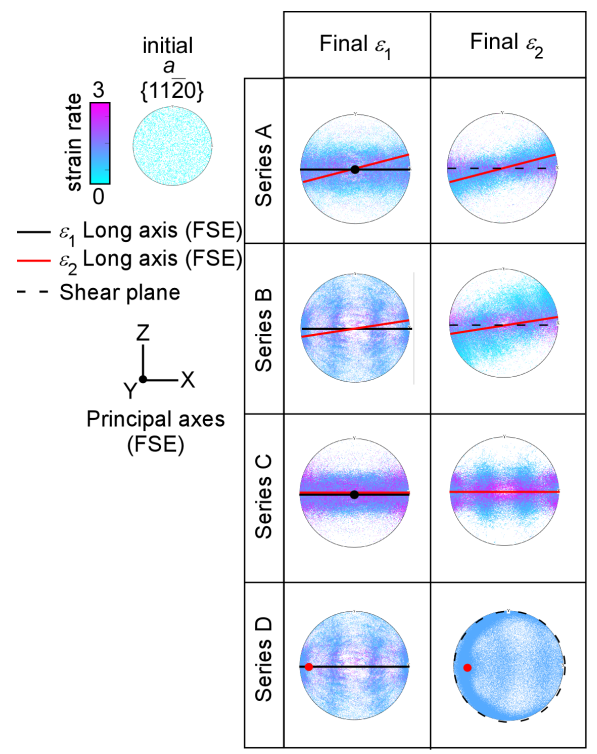

Figure 7. Pole figures of a-axis $\{11-20\}$ orientation at the end of the first stage of deformation $\left(\varepsilon_{l}\right)$ and the beginning and the end of the second stage of deformation $\left(\varepsilon_{2}\right)$ for all series presented. The colour code in pole figures indicates the Von Mises strain rate normalised with respect to the bulk value per point (unode). The orientation of the elongation axis of the finite strain ellipsoid (FSE) is indicated in solid black or red for the first and second stage of deformation, respectively. The shear plane in simple shear simulations is plotted as a black dashed line. When the orientation of the elongation axis and the a-axis CPO is parallel (series C and D), the inherited CPO is not completely overprinted at the end of the simulation.

The development of a vertical single maximum observed in simulations performed under vertical uniaxial compression (first-regime deformation in series A and C) match observations from Antarctic ice core natural samples, as the EPICA Dome C (Durand et al., 2007), Dome F (Azuma et al., 1999), Talos Dome (Montagnat et al., 2012), and Greenland ice cores GISP2 (Gow et al., 1997) and GRIP (Thorsteinsson et al., 1997). They also match laboratory experiments carried out at low temperatures and high strain rates (Craw et al., 2018; Fan et al., 2020). The vertical girdle fabric predicted in our simulations under uniaxial extension (first-regime deformation in series B and D) is also observed in Antarctic and Greenland ice cores, such as the Vostok ice core (Lipenkov et al., 198; Voigt, 2017), EPICA DML (Weikusat et al., 2017), NEEM (Montagnat et al., 2014a) or in the Styx Glacier in Northern Victoria Land (Kim et al., 2020). As described in the NorthGRIP Greenland ice core, the vertical girdle is interpreted as evidence for extension transverse to the ridge, where the vertical girdle plane is oriented perpendicular to the axis of horizontal extension (Wang et al., 2002; Faria et al., 2014; Weikusat et al., 2017). 
The results from plausible scenarios studied here, reveal that when a second deformation regime affects the microstructure the inherited CPO gets overprinted, and the CPO evolves according to the new kinematics of deformation. Regardless of the inherited CPO, our simulations predict a strong c-axis maximum almost perpendicular to the shear plane under simple shear boundary conditions (series A and B). In both series, the a-axes reorient following the elongation axis of the new regime (i.e., long axis of the FSE) with high-strain rate domains oriented parallel to the shear plane (see high-strain orientations in series $\mathrm{A}$ and $B$ in Fig. 7). Following these results, the CPO developed in ice accumulated in a dome or a ridge would be overprinted at depth by the dominance of shearing parallel to the bedrock. These predicted CPOs are in accordance with the observations of CPO analyses from most

415 deep ice drill cores located on sites with the ice frozen to the bed in Antarctica and Greenland, where an approximately vertical single maximum CPO is found (e.g., Faria et al., 2014; Montagnat et al., 2014a; Weikusat et al., 2017).

Simulations predict that the land-based ice CPO is destroyed at the ice shelf, assuming the example of shearing on the vertical plane as the dominant deformation regime, as observed in the Antarctic Amery (Young et al., 2002) or Western Ross ice shelfs (LeDoux et al., 2017; Lutz et al., 2020). In this case, although the inherited vertical girdle CPO is not completely destroyed at the end of the simulation $(\varepsilon=2)$, it is progressively overprinted by the shearing on the vertical plane, (series D in Fig. 7).

When an inherited single vertical maximum is affected by extension along the flow, similar to ice flowing in an ice stream that previously has been accumulated in an ice dome, the CPO is also progressively overprinted, but the required strain is clearly much higher than that for the other cases $(\varepsilon>1.2)$ (series C Fig. 7). Simulations predict that ice moving into a shear margin or potentially developing a shear margin during the initiation of an ice stream, will basically loose its original CPO as shearing on the vertical plane overprints the inherited fabric.

As observed in the simulations, the effectivity of the second flow regime on the reorientation of the CPO depends not only on the strength of the inherited CPO, but also on the relationship between the crystal orientation and the Finite Strain Ellipsoid (FSE) of the new imposed regime. When the inherited a-axis preferred orientation and the elongation axis of the new FSE are parallel (see series C and D in Fig. 7) c-axis orientations are more slowly modified. This is in accordance with our understanding of dislocation motion, because the most efficient dislocations in ice (basal dislocations) do have a Burgers vector component 
(glide direction) along the a-axes.

The flow behaviour from the pole figure observed in Series $\mathrm{C}$ at $\varepsilon_{1}=1.2$ and $\varepsilon_{2}=1.2$ (see lower right corner in Fig. 5a) could easily be misinterpreted as axial compression in the $y$ direction (Fig. 3b), while the true current flow is axial extension in the $x$-direction.

The effectivity of the second flow regime is also observable in the relative activity of slip systems (Fig.8). In all cases, the new imposed regime produces a remarkable increment of basal slip, while the pyramidal slip system activity is reduced (see series A, B and D in Fig.8). A different effect is found when an inherited vertical single maximum is affected by extension along the flow direction, where the basal activity remains constant, and the prismatic slip is increased (see series $\mathrm{C}$ in Fig.8).
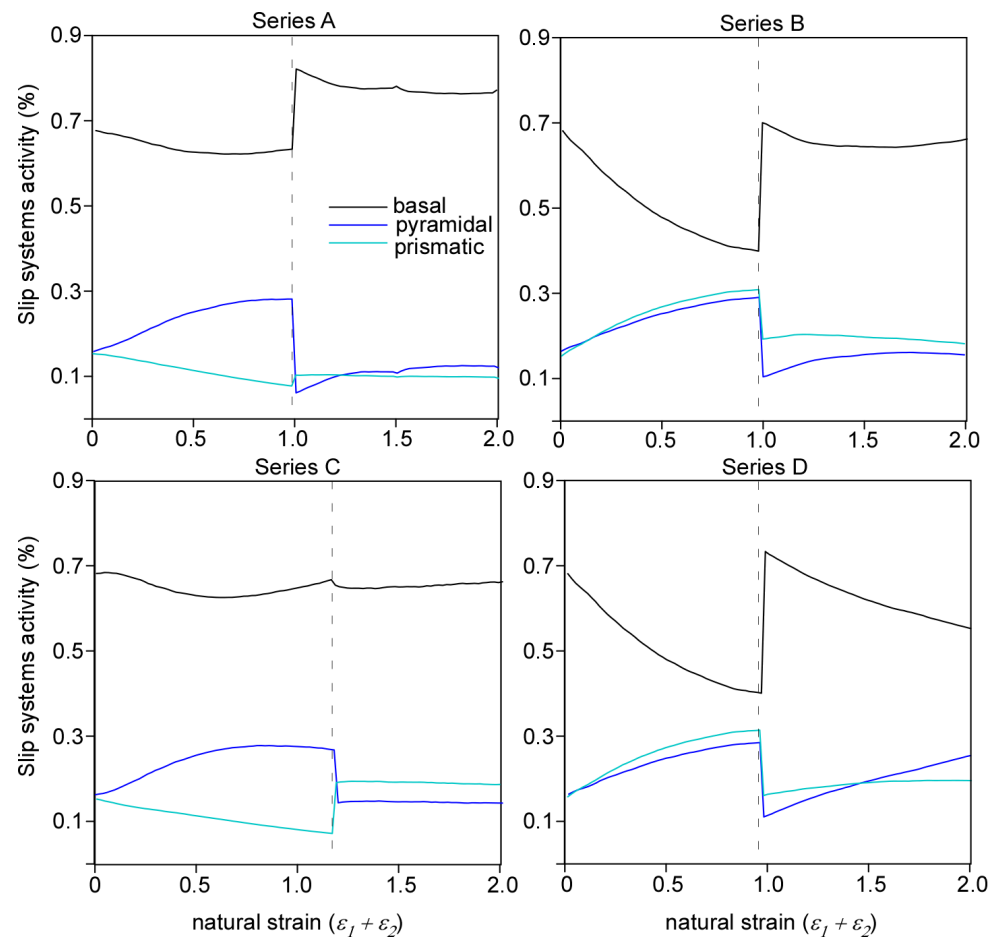

Figure 8. Relative activities of basal, pyramidal and prismatic slip systems during deformation for all series presented, calculated from Equation (1). Transition of deformation regimes are marked.

All these results demonstrate that an inherited CPO can change entirely within strains of $\varepsilon$ $<1.2$ with a range of transition fabrics (Fig.9). Therefore, these simulations do not support the assumption that an inherited $\mathrm{CPO}$ from a previous regime is not destroyed by the current flow (Smith et al., 2017). This process depends on both the intensity of the inherited CPO, and its orientation with respect to the new flow regime. These results are in agreement with ice 
experiments of natural samples with a pre-existing CPO, where the application of a stress field in a non-favourable orientation with respect to the inherited CPO destroys it (Jun and Jacka, 1998, Craw et al., 2018).

460 One particular case is an inherited strong $\mathrm{CPO}$, where a-axes are optimally oriented with respect to the second flow regime, because the FSE elongation axis from the first and second regime are in the same plane (see FSA in series C and D in Fig.8). In this situation the second regime does not produce a rapid re-orientation of the a-axes with respect to the elongation axis, the basal activity is not enhanced and therefore the CPO is only slightly modified (series $\mathrm{C}$ and D in Fig.9). In this case the required finite strain for overprinting the initial CPO is clearly much higher than that for the other cases.

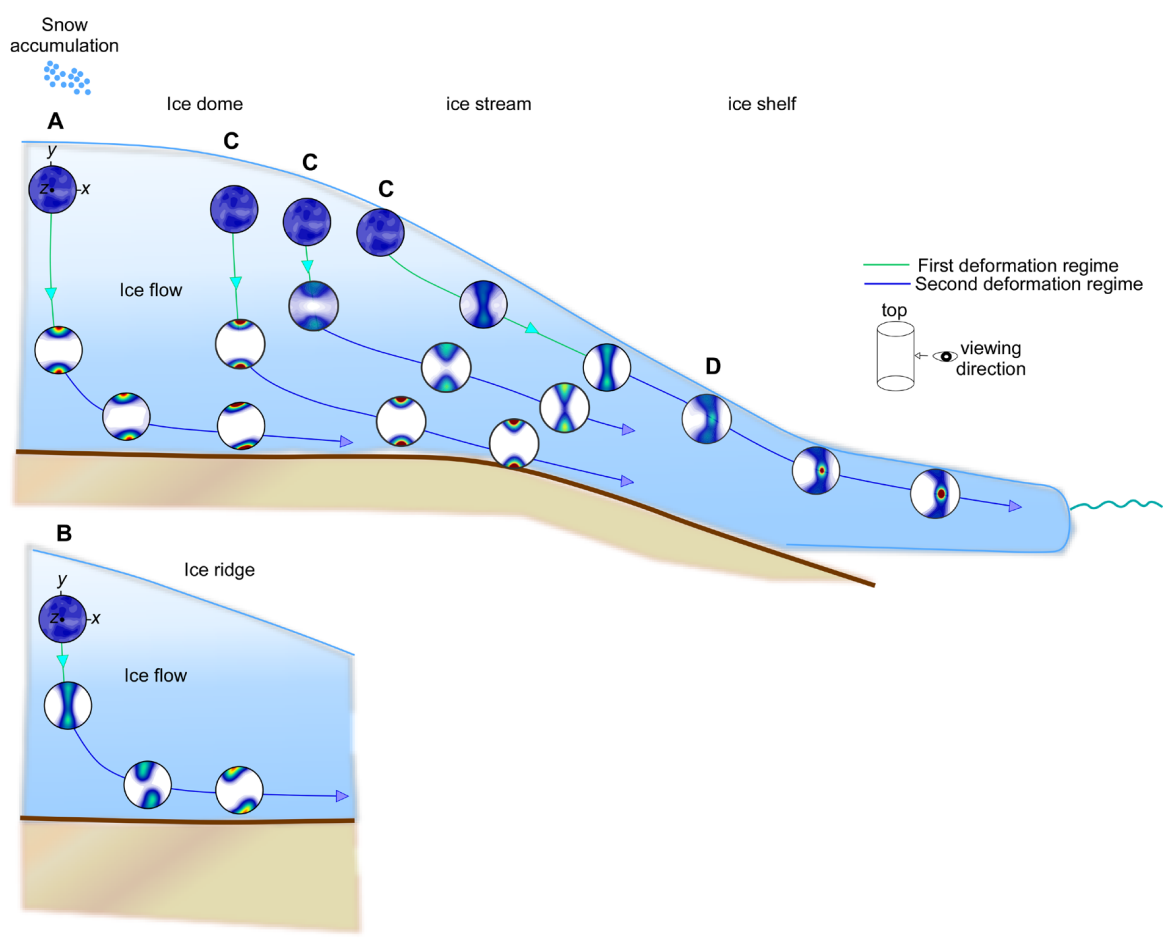

Figure 9. Prediction of evolution of c-axis $\{0001\}$ orientation in all series presented (from A to D), according to the deformation conditions assumed in figure 1. A flow change produces an overprint of the previous CPO, with a range of transition fabrics.

\section{Conclusions}

This study presents a series of full-field numerical simulations of (non-linear viscous) polycrystalline ice deformed under two consecutive flow regimes. The analysis of the 
resulting crystallographic preferred orientation (CPO) leads to the following main conclusions:

1. Simulations with an initial random distribution of crystallographic orientations predict a quick alignment of the crystallographic axes according to the imposed deformation conditions. In all cases, ice polycrystals develop a CPO with $c$-axes mostly oriented parallel to the compression axis, and a-axes oriented parallel to the elongation axis of the finite strain ellipsoid.

2. Depending on the sequence of deformation regimes, an inherited CPO can be completely overprinted by the later deformation event. An inherited CPO can change entirely within natural strain lower than 1.2, with a range of transitional fabrics. This process depends both on the intensity of the inherited $\mathrm{CPO}$ and its orientation with respect to the new stress field. 3. More specifically, when the inherited $a$-axis preferred orientation and the elongation axis of the finite strain ellipse of the flow are parallel, lattice orientation only needs to be reoriented slightly. The required finite strain for overprinting the initial CPO in this configuration is much higher $(\varepsilon>1.2)$ than that for the other cases. This is the case of ice flowing from an ice dome to an ice stream. This situation could lead to a misinterpretation of the second flow regime from observed c-axis preferred orientation.

4. According to these results, ice flow interpretations from observed CPOs can be reliable, but must be carried out with caution in areas with complex (multi-stage) deformation histories.

\section{Acknowledgements}

MGL acknowledges a Juan de la Cierva-Incorporación fellowship (IJC2018-036826-I), the support of the Ramón y Cajal fellowship funded by the Spanish Ministry of Science, Innovation and Universities (RYC2018-026335-I). IW acknowledges the HFG grant no.VHNG-802. This work has been developed using the facilities of the Laboratory of Geodynamic Modelling of GEO3BCN and a computer cluster of the University of Tübingen.

\section{References}

Alley, R.B., Joughin, I. Modeling Ice-Sheet Flow. 2012. Science, 336, 551. 
Azuma, N. and Higashi, A. Mechanical properties of dye 3 Greenland deep ice cores. Annals of glaciology, 5 ,1-8. 1984

Azuma, N., Wang, Y., Mori, K., Narita, H., Hondoh, T., Shoji and H.,Watanabe, O. Textures and fabrics in the Dome F (Antarctica) ice core. Annals of Glaciology, 29, pp.163-168. 1999

Bachmann, F., Hielscher, R. and Schaeben, H. Grain detection from 2d and 3d EBSD dataSpecification of the MTEX algorithm. Ultramicroscopy, 111(12), pp.1720-1733. 2011

Bons, P.D., Koehn, D. and Jessell, M.W. Microdynamic Simulation. Lecture Notes in Earth Sciences 106, Springer, Berlin. 405 pp. 2008

Bons, P.D., Kleiner, T., Llorens, M.G., Prior, D.J., Sachau, T., Weikusat, I. and Jansen, D. Greenland Ice Sheet: Higher nonlinearity of ice flow significantly reduces estimated basal motion. Geophysical Research Letters, 45(13), pp.6542-6548. 2018.

Budd, W. and Jacka, T. A review of ice rheology for ice sheet modelling. Cold Regions Sci. Technol., 16(2), 107-144. doi: 10.1016/0165-232X(89)90014-1. 1989.

Castelnau, O., Shoji, H., Mangeney, A., Milsch, H., Duval, P., Miyamoto, A., Kawada and K.,Watanabe, O. Anisotropic behavior of GRIP ices and flow in central Greenland. Earth and planetary science letters, 154(1-4), pp.307-322. 1998

Craw, L., Qi, C., Prior, D.J., Goldsby, D.L. and Kim, D. Mechanics and microstructure of deformed natural anisotropic ice. J. Struct. Geol. 115, 152-166. 2018

Dahl-Jensen, D., Thorsteinsson, T., Alley, R. and Shoji, H. Flow properties of the ice from the Greenland Ice Core Project ice core: the reason for folds?. Journal of Geophysical Research: Oceans, 102(C12), pp.26831-26840. 1997

Durand, G., Gillet-Chaulet, F., Svensson, A., Gagliardini, O., Kipfstuhl, S., Meyssonnier, J., Parrenin, F., Duval, P. and Dahl-Jensen, D. Change in ice rheology during climate variations-implications for ice flow modelling and dating of the EPICA Dome C core. Climate of the Past, 3(1), pp.155-167. 2007

Durham, W.B., Heard, H.C. and Kirby, S.H. Experimental deformation of polycrystalline $\mathrm{H} 2 \mathrm{O}$ ice at high pressure and low temperature: Preliminary results. Journal of Geophysical Research: Solid Earth, 88(S01), pp.B377-B392. 1983

Duval, P., Ashby, M.F. and Anderman, I. Rate-controlling processes in the creep of polycrystalline ice. The Journal of Physical Chemistry, 87(21), pp.4066-4074. 1983

Edwards, T.L., Nowicki, S., Marzeion, B., Hock, R., Goelzer, H., Seroussi, H., Jourdain, N.C., Slater, D.A., Turner, F.E., Smith, C.J. and McKenna, C.M. Projected land ice contributions to twenty-first-century sea level rise. Nature, 593(7857), pp.74-82. 2021. 
Fan, S., Hager, T.F., Prior, D.J., Cross, A.J., Goldsby, D.L., Qi, C., Negrini and Wheeler, J. Temperature and strain controls on ice deformation mechanisms: insights from the microstructures of samples deformed to progressively higher strains at $-10,-20$ and$30^{\circ}$ C. The Cryosphere, 14(11), pp.3875-3905. 2020

Faria, S. H., Weikusat, I., and Azuma, N. The microstructure of polar ice. Part I: Highlights from ice core research, J. Struct. Geol., 61, 2-20 https://doi.org/10.1016/j.jsg.2013.09.010, 2014

Gao, X.Q. and Jacka, T.H. The approach to similar tertiary creep rates for Antarctic core ice and laboratory prepared ice. Le Journal de Physique Colloques, 48(C1), pp.C1-289. 1987

Golledge, N. R., Kowalewski, D. E., Naish, T. R., Levy, R. H., Fogwill, C. J. and Gasson, E. G. W. The multi-millennial Antarctic commitment to future sea-level rise, Nature, 526, 421-425, https://doi.org/10.1038/nature15706. 2015.

Griera, A., Llorens, M.G., Gomez-Rivas, E., Bons, P.D., Jessell, M.W., Evans, L.A. and Lebensohn, R.. Numerical modelling of porphyroclast and porphyroblast rotation in anisotropic rocks. Tectonophysics, 587, pp.4-29. 2013.

Gow, A.J., Meese, D.A., Alley, R.B., Fitzpatrick, J.J., Anandakrishnan, S., Woods, G.A. and Elder, B.C. Physical and structural properties of the Greenland Ice Sheet Project 2 ice core: A review. Journal of Geophysical Research: Oceans, 102(C12), pp.26559-26575. 1997

Haefeli, R. Contribution to the movement and the form of ice sheets in the Arctic and Antarctic. Journal of Glaciology, 3(30), pp.1133-1151. 1961

Hudleston, P.J. Structures and fabrics in glacial ice: a review. Journal of Structural Geology, 81, pp.1-27. 2015

Jansen, D., Llorens, M.G., Westhoff, J., Steinbach, F., Kipfstuhl, S., Bons, P.D., Griera, A. and Weikusat, I. Small-scale disturbances in the stratigraphy of the NEEM ice core: observations and numerical model simulations. The Cryosphere, 10(1), pp.359-370. 2016

Jun, L. and Jacka, T.H. Horizontal shear rate of ice initially exhibiting vertical compression fabrics. Journal of Glaciology, 44(148), pp.670-672. 1998

Katayama, I. and Karato, S.I. Effect of temperature on the B-to C-type olivine fabric transition and implication for flow pattern in subduction zones. Physics of the Earth and Planetary Interiors, 157(1-2), pp.33-45. 2006 
Kim, D., Prior, D.J., Han, Y., Qi, C., Han, H. and Ju, H.T. Microstructures and Fabric Transitions of Natural Ice from the Styx Glacier, Northern Victoria Land, Antarctica. Minerals, 10(10), p.892. 2020

Lebensohn, R.A. and Rollett, A.D. Spectral methods for full-field micromechanical modelling of polycrystalline materials. Computational Materials Science, 173, p.109336. 2020

Llorens, M. G., Griera, A., Bons, P. D., Roessiger, J., Lebensohn, R., Evans, L. and Weikusat, I. Dynamic recrystallisation of ice aggregates during co-axial viscoplastic deformation: a numerical approach. Journal of Glaciology 62, 359-377. 2016a

Llorens, M. G., Griera, A., Bons, P. D., Lebensohn, R. A., Evans, L. A., Jansen, D. and Weikusat, I. Full field predictions of ice dynamic recrystallisation under simple shear conditions. Earth and Planetary science letters 450, 233-242. 2016b

Llorens, M.G., Gomez-Rivas, E., Ganzhorn, A.C., Griera, A., Steinbach, F., Roessiger, J., Labrousse, L., Walte, N.P., Weikusat, I. and Bons, P.D. The effect of dynamic recrystallisation on the rheology and microstructures of partially molten rocks. Journal of Structural Geology, 118, pp.224-235. 2019

Llorens, M.G., Griera, A., Bons, P.D., Gomez-Rivas, E., Weikusat, I., Prior, D.J., Kerch, J. and Lebensohn, R.A. Seismic anisotropy of temperate ice in polar ice sheets. Journal of Geophysical Research: Earth Surface, 125(11), p.e2020JF005714. 2020

LeDoux, C.M., Hulbe, C.L., Forbes, M.P., Scambos, T.A. and Alley, K. Structural provinces of the ross ice shelf, antarctica. Annals of Glaciology, 58(75pt1), pp.88-98. 2017

Lipenkov, V.Y., Barkov, N.I., Duval, P. and Pimienta, P. Crystalline Texture of the $2083 \mathrm{~m}$ Ice Core at Vostok Station, Antarctica. J. Glaciol., 35, 392-398. 1989

Lutz, F., Eccles, J., Prior, D.J., Craw, L., Fan, S., Hulbe, C., Forbes, M., Still, H., Pyne, A. and Mandeno, D. Constraining Ice Shelf Anisotropy Using Shear Wave Splitting Measurements from Active-Source Borehole Seismics. Journal of Geophysical Research: Earth Surface, 125(9), p.e2020JF005707. 2020

Montagnat, M., Buiron, D., Arnaud, L., Broquet, A., Schlitz, P., Jacob, R. and Kipfstuhl, S. Measurements and numerical simulation of fabric evolution along the Talos Dome ice core, Antarctica. Earth and Planetary Science Letters, 357, pp.168-178. 2012

Montagnat, M., Azuma, N., Dahl-Jensen, D., Eichler, J., Fujita, S., Gillet-Chaulet, F., Kipfstuhl, S., Samyn, D., Svensson, A. and Weikusat, I. Fabric along the NEEM ice core, Greenland, and its comparison with GRIP and NGRIP ice cores. 2014a 
Montagnat, M., Castelnau, O., Bons, P.D., Faria, S.H., Gagliardini, O., Gillet-Chaulet, F., Grennerat, F., Griera, A., Lebensohn, R.A., Moulinec, H., Roessiger, J. and Suquet, P. Multiscale modeling of ice deformation behavior. Journal of Structural Geology 61, 78108. dx.doi.org/10.1016/j.jsg.2013.05.002. 2014b

Nerem, R.S., Beckley, B.D., Fasullo, J.T., Hamlington, B.D., Masters, D. and Mitchum, G.T. Climate-change-driven accelerated sea-level rise detected in the altimeter era. Proceedings of the national academy of sciences, 115(9), pp.2022-2025. 2018

Passchier, C.W. Reconstruction of deformation and flow parameters from deformed vein sets. Tectonophysics 180, 185- 199. 1990.

Piazolo, S., Bons, P.D., Griera, A., Llorens, M.G., Gomez-Rivas, E., Koehn, D., Wheeler, J., Gardner, R., Godinho, J.R., Evans, L. and Lebensohn, R.A. A review of numerical modelling of the dynamics of microstructural development in rocks and ice: Past, present and future. Journal of Structural Geology, 125, pp.111-123. 2019

Qi, C., Prior, D.J., Craw, L., Fan, S., Llorens, M.G., Griera, A., Negrini, M., Bons, P.D. and Goldsby, D.L. Crystallographic preferred orientations of ice deformed in direct-shear experiments at low temperatures. The Cryosphere, 13(1), pp.351-371. 2019

Smith, E.C., Baird, A.F., Kendall, J.M., Martín, C., White, R.S., Brisbourne, A.M. and Smith, A.M. Ice fabric in an Antarctic ice stream interpreted from seismic anisotropy. Geophysical Research Letters, 44(8), pp.3710-3718. 2017

Skemer, P., Katayama, I., Jiang, Z. and Karato, S.I. The misorientation index: Development of a new method for calculating the strength of lattice-preferred orientation. Tectonophysics, 411(1-4), pp.157-167. 2005

Steinbach, F., Bons, P.D., Griera, A., Jansen, D., Llorens, M.G., Roessiger, J. and Weikusat, I. Strain localization and dynamic recrystallization in the ice-air aggregate: a numerical study. The Cryosphere, 10(6), pp.3071-3089. 2016

Thorsteinsson, T., Kipfstuhl, J. and Miller, H. Textures and fabrics in the GRIP ice core. J. Geophys. Res. Ocean. 102, 26583-26599. 1997

Treverrow, A., Budd, W.F., Jacka, T.H. amd Warner R.C. The tertiary creep of polycrystalline ice: experimental evidence for stress dependent levels of strain rate enhancement. J. Glaciol., 58 (208), 301-314. doi: 10.3189/2012JoG11J149. 2012

Young, N.W. and Hyland, G. Velocity and strain rates derived from InSAR analysis over the Amery Ice Shelf, East Antarctica. Annals of Glaciology, 34, pp.228-234. 2002

Voigt, D.E. c-Axis Fabric of the South Pole Ice Core, SPC14. U.S. Antarctic Program (USAP) Data Center. doi: https://doi.org/10.15784/601057. 2017 
https://doi.org/10.5194/tc-2021-224

Preprint. Discussion started: 17 September 2021

(C) Author(s) 2021. CC BY 4.0 License.

Wang, Y., Thorsteinsson, T., Kipfstuhl, J., Miller, H., Dahl-Jensen, D. and Shoji, H. A

Vostok-type fabric in the NGRIP deep ice core, North Greenland. Ann. Glaciol. 2002

Weikusat, I., Jansen, D., Binder, T., Eichler, J., Faria, S.H., Wilhelms, F., Kipfstuhl, S.,

Sheldon, S., Miller, H., Dahl-Jensen and D., Kleiner, T. Physical analysis of an

Antarctic ice core- towards an integration of micro-and macrodynamics of polar ice.

Philosophical Transactions of the Royal Society A, 375(2086), p.20150347. 2017 